\title{
Getting in and Staying Alive: Role for Coronin 1 in the Survival of Pathogenic Mycobacteria and Naïve T Cells
}

\author{
Mayumi Mori and Jean Pieters* \\ Biozentrum, University of Basel, Basel, Switzerland
}

There are many different pathogenic stimuli that are able to activate the immune system, ranging from microbes that include bacteria, viruses, fungi, and parasites to host-derived triggers such as autoantigens that can induce autoimmunity as well as neoantigens involved in tumorigenesis. One of the key interactions shaping immunity toward these

OPEN ACCESS

Edited by:

Rhodri Ceredig,

National University of Ireland

Galway, Ireland

Reviewed by:

Salvatore Valitutti,

Institut National de la Santé et

de la Recherche Médicale

(INSERM), France

Martin Turner,

Babraham Institute (BBSRC),

United Kingdom

Nick Gascoigne,

National University of Singapore,

Singapore

*Correspondence:

Jean Pieters

jean.pieters@unibas.ch

Specialty section:

This article was submitted

to T Cell Biology,

a section of the journal

Frontiers in Immunology

Received: 01 May 2018

Accepted: 27 June 2018

Published: 10 July 2018

Citation:

Mori M and Pieters J (2018) Getting

in and Staying Alive: Role for Coronin

1 in the Survival of Pathogenic

Mycobacteria and Naive T Cells.

Front. Immunol. 9:1592.

doi: 10.3389/fimmu.2018.01592 triggers involves the encounter of antigen-processing and -presenting cells such as macrophages and dendritic cells with $T$ cells, resulting in immune responses that are highly selective for the antigenic trigger. Research over the past few years has implicated members of the coronin protein family, in particular coronin 1, in responses against several pathogenic triggers. While coronin 1 was initially described as a host factor allowing the intracellular survival of the pathogen Mycobacterium tuberculosis, subsequent work showed it to be a crucial factor for naïve $T$ cell homeostasis. The activity of coronin 1 in allowing the intracellular survival of pathogenic mycobacteria is relatively well characterized, involving the activation of the $\mathrm{Ca}^{2+}$ /calcineurin pathway, while coronin 1's role in modulating naïve $T$ cell homeostasis remains more enigmatic. In this mini review, we discuss the knowledge on the role for coronin 1 in immune cell functioning and provide a number of potential scenarios via which coronin 1 may be able to regulate naïve $T$ cell homeostasis.

Keywords: coronin 1, macrophages, Mycobacterium tuberculosis, naïve T cell homeostasis, interleukin 7, T cell receptor

\section{INTRODUCTION}

The vertebrate immune system has evolved to efficiently deal with both intracellular and extracellular pathogens to ensure a battery of defense strategies, both through innate and adaptive mechanisms. The innate immune defense arm can react rapidly as a result of the recruitment of neutrophils, natural killer cells, dendritic cells, and macrophages to the site of infection. These cells not only ensure the direct elimination of the pathogens but also aid in the activation of adaptive immunity by inducing the proliferation, maturation, and expansion of $\mathrm{B}$ and $\mathrm{T}$ lymphocytes. The concerted action of innate and adaptive immune cells results in an effective clearance of microbial and parasitic pathogens; however, several pathogens have evolved to withstand such immune detection, sometimes by hijacking the immune system at several levels.

For many bacterial pathogens, the initial and often fatal encounter is their interaction with macrophages. These cells are the scavengers of the vertebrate immune system, and typically digest any microbe following their internalization through phagocytosis and delivery to lysosomes and/or 
autophagosomes $(1,2)$. Following digestion, pathogen-derived antigens (peptides, lipids, and metabolites) can be bound to the so-called antigen-presenting molecules of the major histocompatibility complex (MHC) class I and class II, cluster of differentiation 1 (CD1), or MHC class I-related protein MR1 complexes, which are then re-routed to the plasma membrane where these antigens can be presented to $\mathrm{T}$ lymphocytes. This interaction between antigen-presenting cells and $\mathrm{T}$ cells subsequently triggers $\mathrm{T}$ cell proliferation/expansion in an antigen-specific manner (3-6). One particularly notorious pathogen, Mycobacterium tuberculosis, which is transmitted through aerosols and is phagocytosed by alveolar macrophages, has evolved to hijack this process of intracellular degradation, thereby converting the normal hostile environment of the macrophage into a safe haven. M. tuberculosis does so using multiple strategies, including the attenuation of macrophage inflammatory signaling cascades, neutralization of reactive oxygen and nitrogen species, as well as altering its metabolic state (7-10). As a result, instead of being degraded within macrophages, $M$. tuberculosis manages to survive for a prolonged time within these cells, often in a so-called dormant state, and can become reactivated when the health of an infected person deteriorates, for example, following food deprivation or inflammatory stress, such as co-infection by HIV. Apart from its ability to survive within macrophage phagosomes, M. tuberculosis has been reported to be released into the macrophage cytosol, where it can activate a number of mechanisms leading to cell death, allowing the dissemination of the bacilli to neighboring cells (11). The capacity of $M$. tuberculosis to withstand intracellular delivery to lysosomes and degradation was initially realized from electron micrographs of M. tuberculosis-infected macrophages (12) and has been widely recognized as a major strategy employed by $M$. tuberculosis to establish long-term infections.

\section{IDENTIFICATION OF CORONIN 1 AS A SURVIVAL FACTOR FOR INTRACELLULARLY RESIDING MYCOBACTERIA}

Given the central importance for $M$. tuberculosis to prevent intracellular delivery to lysosomes for the establishment of a long-term infection, it is not surprising that mycobacteria utilize a number of different strategies to achieve this $(8,9,13)$. One of these strategies was found to be the recruitment and retention of a host protein, coronin 1 (also known as P57 or TACO, for Tryptophan Aspartate containing Coat protein), to the cytosolic side of the mycobacterial phagosome. Coronin 1 is expressed in all hematopoietic cell types and is a member of the widely conserved coronin protein family, members of which are expressed in virtually all eukaryotic species $(14,15)$. The recruitment of coronin 1 activates the calcium/calcineurin pathway that was shown to block phagosome-lysosome fusion and the degradation of the internalized mycobacteria $(16,17)$. The precise mechanism via which calcineurin, a ubiquitously expressed phosphatase, modulates intracellular mycobacterial survival remains to be identified, and it is possible that calcineurin acts in concert with several of the other factors that have been identified to allow $M$. tuberculosis survival within macrophages, including kinases, lipids, metabolites, and signaling molecules (18-23). Coronin 1-dependent modulation of lysosomal trafficking appears to be specific for mycobacteria, since several other types of cargo are readily delivered to lysosomes in a coronin 1 -independent manner (16).

The role for coronin 1 in protecting $M$. tuberculosis from intracellular death within macrophages was corroborated by analyzing mice that lack the gene coding coronin 1 (corola). In macrophages derived from these mice, mycobacteria are readily transferred to lysosomes followed by their destruction (16). However, other than the inability of coronin 1-deficient macrophages to support the intracellular survival of pathogenic mycobacteria, macrophages devoid of coronin 1 appear to be fully functional in terms of phagocytosis, endocytosis, motility, membrane ruffling, and migration $(16,24)$. This is also notable because coronin family members have been widely implicated in regulation of the F-actin cytoskeleton (25). The reasons for the absence of F-actin-dependent phenotypes in macrophages devoid of coronin 1 may lie within (i) the fact that other coronin family members with redundant roles are co-expressed in macrophages, (ii) a function for coronin 1 upstream of F-actin modulation, or (iii) differences in experimental protocols used to analyze coronin 1's function in macrophages. Interestingly, upon macrophage activation as occurs during an inflammatory stimulus, coronin 1 functions to switch the mode of uptake from phagocytosis to macropinocytosis, thereby enabling macrophages to rapidly internalize large amount of cargo and shuttling these to lysosomes for degradation $(26,27)$. Thus, it appears that M. tuberculosis, perhaps in the course of its long-term coevolution with their mammalian hosts, has gained the capacity to utilize coronin 1-dependent arrest of phagosome-lysosome fusion to allow long-term survival within macrophages, that are precisely those cells destined to destroy any incoming bacilli.

\section{PERIPHERAL T CELL SURVIVAL AND CORONIN 1}

The availability of mice lacking coronin 1 also allowed the analysis of other hematopoietic cell types with respect to their dependence on coronin 1 for proper functioning. Strikingly, whereas virtually all other cell types appear to be unaffected by the absence of coronin 1 , there is one notable exception: mice devoid of coronin 1 are profoundly deficient in $\mathrm{T}$ cells (28-31). Interestingly, this T cell deficiency is exclusively found in peripheral lymphoid organs: T cell development and selection, as for example occurring in the thymus, is not affected by the absence of coronin 1 (32). Several explanations have been put forward to explain the peripheral $\mathrm{T}$ cell deficiency in mice lacking coronin 1: first, the above-mentioned role for coronin proteins in modulating F-actin was suggested to be responsible for inducing $\mathrm{T}$ cell death, via a proposed role for coronin 1 in reducing F-actin levels, in the absence of which elevated F-actin may act to induce cell death (28). However, subsequent work showed that in leukocytes coronin 1 does not modulate F-actin, 
and furthermore that accumulation of F-actin does not correlate with the induction of cell death $(30,33)$. Alternatively, coronin 1 may be involved in the transduction of signals downstream of the T cell receptor (TCR), in the absence of which pro-apoptotic, rather than pro-survival signals, are being activated $(29,30,33)$. Such a pro-survival role for coronin 1 must be selective for peripheral naïve $\mathrm{T}$ cells, since both thymic selection and effector/memory $\mathrm{T}$ cells do not depend on coronin 1 for either survival or functionality $(29,32)$.

\section{HOMEOSTATIC CONTROL OF PERIPHERAL NAÏVE T CELL NUMBERS}

As mentioned above, while peripheral CD4 and CD8 positive $\mathrm{T}$ cells are profoundly depleted upon coronin 1 inactivation, $\mathrm{T}$ cell development and selection in bone marrow and thymus is virtually undisturbed. This is a surprising observation since two of the main drivers of naïve $\mathrm{T}$ cell homeostasis, namely, MHC:TCR signaling and interleukin (IL)-7:IL-7 receptor (IL7R) signaling are both important for thymic T-cell survival (34). Thus, either these signaling pathways require coronin 1 exclusively in peripheral lymphoid organs or, alternatively, coronin 1 is involved in an as yet undefined pathway responsible for peripheral naïve T cell survival.

Homeostatic proliferation and survival are differently controlled between naïve and memory T cells and between CD4 and CD8 T cells (35). For the discussion here, we focus on the naïve CD4 T cell subset, which is most severely suppressed in coronin 1-deficient mice. The mechanisms that have been suggested to maintain naïve CD4 T cells include, besides the aforementioned IL-7 signaling and MHC-TCR interaction, other signaling pathways such as those involving IL-2, 15, and type I interferons, although these appear to be involved to a lesser extent (34, 36-38).

Interleukin-7 has a central role in early lymphopoiesis in the thymus to drive the selection of CD8 lineage-committed cells (39-41). IL-7 does so, via activation of the IL7R pathway, through induction of the expression of the pro-survival factor $\mathrm{Bcl} 2$ and inhibiting the pro-apoptotic factors Bad and Bax. Regarding the role for IL-7 on maintenance of the peripheral naïve CD4 T cell pool, there are conflicting data in the literature. In support of a role for IL-7 in naïve CD4 T cell survival, Tan et al. demonstrated a failure of transferred $\mathrm{T}$ cells to survive when adoptively transferred to IL-7-deficient mice (42). Also, overexpression of IL-7 was shown to enhance T cell proliferation in a lymphopenic mouse model (43). Furthermore, several studies documented enhanced peripheral $\mathrm{T}$ cell proliferation upon overexpression of IL-7 or the IL7R $(44,45)$, although this was not observed in all animal models (46). Furthermore, in vivo infusion of IL-7 results in increased naïve CD4 T cell numbers, although the effect on CD8 T cells is many-fold higher (47-49). On the other hand, a number of studies have reported that IL-7 is dispensable for CD4 T cell proliferation and survival; for example, blockade of the IL-7 receptor alpha chain (IL-7R $\alpha$ ) inhibits only a minor population of low-rate proliferating naïve CD4 $\mathrm{T}$ cells after transfer to RAG2-deficient recipients, without affecting the high-rate proliferating cells (50). Also, while administration of anti-IL-7 antibodies reduces the survival of peripheral CD4 positive T cell numbers (51), it does so only when IL-4 is also depleted (52), suggesting redundant roles for cytokines sharing the common receptor gamma chain $\left(\gamma_{c}\right)$. Conversely, more recent work using a xenogeneic model suggests that increasing IL-7 signaling does not affect peripheral $\mathrm{T}$ cell numbers while it does modulate $\mathrm{T}$ cell development in the thymus (53). Furthermore, conditional genetic deletion of IL-7R $\alpha$ or $\gamma_{c}$ at the late-stage of thymic development, circumventing the suppressive effect on early lymphopoiesis, showed only minimal reduction in CD4 single positive thymocytes, compared with a profound reduction of CD8 single positive T cells, whereas peripheral naïve CD4 $\mathrm{T}$ cell numbers have not been addressed in these studies $(54,55)$. Finally, it has been proposed that rather than a direct availability of IL-7 to CD4 T cells, IL-7 signaling on antigen-presenting cells may be the main driver of homeostatic proliferation of naïve CD4 T cells in vivo $(56,57)$.

Thus, while the role for IL-7 in CD8 T cell lineage selection in the thymus is clearly established, it appears to be dispensable for CD4 T cell lineage selection, and an exclusive role for this cytokine in the maintenance of peripheral naive CD4 T cell survival is unclear. Perhaps, IL-7 is mainly required for depletion-induced ("homeostatic") proliferation rather than maintenance of $\mathrm{T}$ cell numbers under non-perturbed situations. Given the normal thymic $\mathrm{T}$ cell development observed in mice lacking coronin 1 (32), it is unlikely that coronin 1 plays a role directly downstream of IL-7 signaling. However, it is possible that coronin 1 works in concert with IL-7 signaling to allow peripheral naïve CD4 T cell survival.

The second trigger that is widely reported to be involved in naïve CD4 T cell survival is TCR signaling by MHC:peptide complexes. While, similar to IL-7 signaling, MHC molecules play a crucial role during thymic selection $(58,59)$, several studies have reported that MHC molecules are important for peripheral $\mathrm{T}$ cell survival and proliferation (60-62). In particular, peptides loaded on MHC, possibly self-ligands, were considered to be crucial for homeostatic expansion of CD4 T cells, as shown by reduced expansion in hosts that lack peptide presentation on MHCII $(63,64)$, suggesting that specific TCR-MHC interaction is important.

Besides the aforementioned studies that report a role for MHC molecules in the survival and proliferation of naïve $\mathrm{T}$ cells, there are several studies suggesting that naïve $\mathrm{T}$ cell survival is MHC independent. For example, both survival and proliferation of peripheral CD4 $\mathrm{T}$ cells have been reported to occur in the absence of MHC class II molecules $(65,66)$. In addition, another study indicates that MHC may be important for proliferation but not for survival of naïve CD4 T cells (67), considering also the long half-life of $\mathrm{T}$ cells after depletion of MHC class II molecules $(68,69)$.

Regarding the role for peptide presentation on MHC class II molecules, one study using the same $\mathrm{H} 2 \mathrm{M}$-deficient system as Viret et al. (63) have shown dispensability of peptide ligands for peripheral $\mathrm{T}$ cell survival (68). Moreover, DC-T cell synapse accompanied with polarized PKC $\theta$ phosphorylation, indicating the existence of TCR signaling, was detected without antigens or MHC itself (66). Thus, T cell responses supposed 
to be important for peripheral $\mathrm{T}$ cell survival and homeostatic proliferation may not require interaction with cognate peptide-MHC complexes.

As described above, arguments have been brought forward both in favor of and against a role for MHC class II molecules in naïve $\mathrm{T}$ cell survival. What exactly underlies the discrepancy between these opposing results, that in part were obtained using the same experimental model [for example, the same H2M-deficient mouse was used to conclude for and against a role of MHC class II in T cell survival, see Ref. $(63,68)]$, remains to be analyzed and could lie within an inability to distinguish survival and proliferation, the usage of mice deficient in different components of MHC, or the subtype of peripheral T cells analyzed (e.g., naïve versus memory) (70-72). Interestingly, even in the complete absence of MHC class II molecules in both mice and man, peripheral naïve $\mathrm{T}$ cells can be maintained, even for prolonged times (72-74).

Thus, the extent to which MHC-peptide:TCR interaction is important for peripheral naïve CD4 T cell survival remains unclear. Given the normal thymic development of $\mathrm{T}$ cell precursors in mice deficient in coronin 1 and the important role for MHC-TCR signaling in that process, it is unlikely that coronin 1 plays a prominent role in MHC-dependent $\mathrm{T}$ cell activation to generate mature $\mathrm{T}$ cells. Whether the role for coronin 1 in the maintenance of peripheral $\mathrm{T}$ cells involves intracellular events downstream of TCR remains to be analyzed (29). Coronin 1 has been suggested to act through activation

\section{REFERENCES}

1. Weiss G, Schaible UE. Macrophage defense mechanisms against intracellular bacteria. Immunol Rev (2015) 264:182-203. doi:10.1111/imr.12266

2. Taylor PR, Martinez-Pomares L, Stacey M, Lin HH, Brown GD, Gordon S. Macrophage receptors and immune recognition. Annu Rev Immunol (2005) 23:901-44. doi:10.1146/annurev.immunol.23.021704.115816

3. Blum JS, Wearsch PA, Cresswell P. Pathways of antigen processing. Annu Rev Immunol (2013) 31:443-73. doi:10.1146/annurev-immunol-032712-095910

4. Roche PA, Furuta K. The ins and outs of MHC class II-mediated antigen processing and presentation. Nat Rev Immunol (2015) 15:203-16. doi:10.1038/ nri3818

5. Major AS, Joyce S, Van Kaer L. Lipid metabolism, atherogenesis and CD1-restricted antigen presentation. Trends Mol Med (2006) 12:270-8. doi:10.1016/j.molmed.2006.04.004

6. Mori L, Lepore M, De Libero G. The immunology of CD1- and MR1-restricted T cells. Annu Rev Immunol (2016) 34:479-510. doi:10.1146/annurev-immunol032414-112008

7. Nathan C. Role of iNOS in human host defense. Science (2006) 312:1874-5; author reply 1874-5. doi:10.1126/science.312.5782.1874b

8. Rohde K, Yates RM, Purdy GE, Russell DG. Mycobacterium tuberculosis and the environment within the phagosome. Immunol Rev (2007) 219:37-54. doi:10.1111/j.1600-065X.2007.00547.x

9. Pieters J. Mycobacterium tuberculosis and the macrophage: maintaining a balance. Cell Host Microbe (2008) 3:399-407. doi:10.1016/j.chom.2008.05.006

10. Zondervan NA, van Dam JCJ, Schaap PJ, Martins Dos Santos VAP, Suarez-Diez M. Regulation of three virulence strategies of Mycobacterium tuberculosis: a success story. Int J Mol Sci (2018) 19:347. doi:10.3390/ijms19020347

11. Stutz MD, Clark MP, Doerflinger M, Pellegrini M. Mycobacterium tuberculosis: rewiring host cell signaling to promote infection. J Leukoc Biol (2018) 103:259-68. doi:10.1002/JLB.4MR0717-277R

12. Armstrong JA, Hart PD. Phagosome-lysosome interactions in cultured macrophages infected with virulent tubercle bacilli. Reversal of the usual nonfusion pattern and observations on bacterial survival. J Exp Med (1975) 142:1-16. doi:10.1084/jem.142.1.1 of calcium/calcineurin signaling and through modulation of the cytoskeleton $(16,28-31,33)$, but how, exactly, defects in these pathways would result in such a selective phenotype (peripheral naïve $\mathrm{T}$ cell deficiency) remains unclear. It should also be mentioned that little is known about the molecular mechanisms underlying the transition from semi-mature single positive thymocytes to mature naïve T cells in the periphery (75). Future work exploring a possible role for coronin 1 in both the above described IL-7 and MHC-TCR signaling as well as yet unexplored pathways may allow to shed light not only on the molecular mechanisms in which coronin 1 is involved but also possibly contribute to a better understanding of peripheral naïve $\mathrm{T}$ cell homeostasis.

\section{AUTHOR CONTRIBUTIONS}

MM and JP conceived and wrote the paper.

\section{ACKNOWLEDGMENTS}

We thank Rajesh Jayachandran, Ravindra Mode, and Tohnyui Ndinyanka Fabrice for critical comments on the manuscript. Work in the Pieters Laboratory is supported by the Swiss National Science Foundation, the Swiss Multiple Sclerosis Society, the Novartis Foundation for Medical-Biological Research, the Gebert Ruef Foundation, and the Canton of Basel.

13. Warner DF, Mizrahi V. The survival kit of Mycobacterium tuberculosis. Nat Med (2007) 13:282-4. doi:10.1038/nm0307-282

14. Eckert C, Hammesfahr B, Kollmar M. A holistic phylogeny of the coronin gene family reveals an ancient origin of the tandem-coronin, defines a new subfamily, and predicts protein function. BMC Evol Biol (2011) 11:268. doi:10.1186/1471-2148-11-268

15. Pieters J, Muller P, Jayachandran R. On guard: coronin proteins in innate and adaptive immunity. Nat Rev Immunol (2013) 13:510-8. doi:10.1038/nri3465

16. Jayachandran R, Sundaramurthy V, Combaluzier B, Mueller P, Korf H, Huygen K, et al. Survival of mycobacteria in macrophages is mediated by coronin 1-dependent activation of calcineurin. Cell (2007) 130:37-50. doi:10.1016/j. cell.2007.04.043

17. Ferrari G, Langen H, Naito M, Pieters J. A coat protein on phagosomes involved in the intracellular survival of mycobacteria. Cell (1999) 97:435-47. doi:10.1016/S0092-8674(00)80754-0

18. Scherr N, Pieters J. The eukaryotic-like serine/threonine protein kinase family in mycobacteria. In: Parish T, Brown A, editors. Mycobacterium: Genomics and Molecular Biology. Poole: Horizon Scientific Press (2009). p. 171-88.

19. Vergne I, Fratti RA, Hill PJ, Chua J, Belisle J, Deretic V. Mycobacterium tuberculosis phagosome maturation arrest: mycobacterial phosphatidylinositol analog phosphatidylinositol mannoside stimulates early endosomal fusion. Mol Biol Cell (2004) 15:751-60. doi:10.1091/mbc.e03-05-0307

20. Walburger A, Koul A, Ferrari G, Nguyen L, Prescianotto-Baschong C, Huygen K, et al. Protein kinase $\mathrm{G}$ from pathogenic mycobacteria promotes survival within macrophages. Science (2004) 304:1800-4. doi:10.1126/science.1099384

21. Agarwal N, Lamichhane G, Gupta R, Nolan S, Bishai WR. Cyclic AMP intoxication of macrophages by a Mycobacterium tuberculosis adenylate cyclase. Nature (2009) 460:98-102. doi:10.1038/nature08123

22. Shenoy AR, Visweswariah SS. New messages from old messengers: cAMP and mycobacteria. Trends Microbiol (2006) 14:543-50. doi:10.1016/j. tim.2006.10.005

23. Chao J, Wong D, Zheng X, Poirier V, Bach H, Hmama Z, et al. Protein kinase and phosphatase signaling in Mycobacterium tuberculosis physiology and pathogenesis. Biochim Biophys Acta (2010) 1804:620-7. doi:10.1016/j. bbapap.2009.09.008 
24. Jayachandran R, Gatfield J, Massner J, Albrecht I, Zanolari B, Pieters J. RNA interference in $\mathrm{J774}$ macrophages reveals a role for coronin 1 in mycobacterial trafficking but not in actin-dependent processes. Mol Biol Cell (2008) 19:1241-51. doi:10.1091/mbc.e07-07-0640

25. de Hostos EL. The coronin family of actin-associated proteins. Trends Cell Biol (1999) 9:345-50. doi:10.1016/S0962-8924(99)01620-7

26. BoseDasgupta S, Moes S, Jenoe P, Pieters J. Cytokine-induced macropinocytosis in macrophages is regulated by 14-3-3zeta through its interaction with serine-phosphorylated coronin 1. FEBS J (2015) 282:1167-81. doi:10.1111/ febs. 13214

27. Bosedasgupta S, Pieters J. Inflammatory stimuli reprogram macrophage phagocytosis to macropinocytosis for the rapid elimination of pathogens. PLoS Pathog (2014) 10:e1003879. doi:10.1371/journal.ppat.1003879

28. Foger N, Rangell L, Danilenko DM, Chan AC. Requirement for coronin 1 in T lymphocyte trafficking and cellular homeostasis. Science (2006) 313:839-42. doi:10.1126/science. 1130563

29. Mueller P, Massner J, Jayachandran R, Combaluzier B, Albrecht I, Gatfield J, et al. Regulation of $\mathrm{T}$ cell survival through coronin-1-mediated generation of inositol-1,4,5-trisphosphate and calcium mobilization after $\mathrm{T}$ cell receptor triggering. Nat Immunol (2008) 9:424-31. doi:10.1038/ni1570

30. Haraldsson MK, Louis-Dit-Sully CA, Lawson BR, Sternik G, SantiagoRaber ML, Gascoigne NR, et al. The lupus-related Lmb3 locus contains a disease-suppressing coronin-1A gene mutation. Immunity (2008) 28:40-51. doi:10.1016/j.immuni.2007.11.023

31. Shiow LR, Roadcap DW, Paris K, Watson SR, Grigorova IL, Lebet T, et al. The actin regulator coronin $1 \mathrm{~A}$ is mutant in a thymic egress-deficient mouse strain and in a patient with severe combined immunodeficiency. Nat Immunol (2008) 9:1307-15. doi:10.1038/ni.1662

32. Lang MJ, Mori M, Ruer-Laventie J, Pieters J. A coronin 1-dependent decision switch in juvenile mice determines the population of the peripheral naïve $\mathrm{T}$ cell compartment. J Immunol (2017) 199:2421-31. doi:10.4049/jimmunol.1700438

33. Mueller P, Liu X, Pieters J. Migration and homeostasis of naïve T cells depends on coronin 1-mediated prosurvival signals and not on coronin 1-dependent filamentous actin modulation. J Immunol (2011) 186:4039-50. doi:10.4049/ jimmunol.1003352

34. Surh CD, Sprent J. Homeostasis of naïve and memory T cells. Immunity (2008) 29:848-62. doi:10.1016/j.immuni.2008.11.002

35. Boyman O, Letourneau S, Krieg C, Sprent J. Homeostatic proliferation and survival of naïve and memory T cells. Eur J Immunol (2009) 39:2088-94. doi:10.1002/eji.200939444

36. Purton JF, Sprent J, Surh CD. Staying alive - naïve CD4(+) T cell homeostasis. Eur J Immunol (2007) 37:2367-9. doi:10.1002/eji.200737721

37. Sprent J, Surh CD. Normal T cell homeostasis: the conversion of naïve cells into memory-phenotype cells. Nat Immunol (2011) 12:478-84. doi:10.1038/ ni.2018

38. Boyman O, Krieg C, Homann D, Sprent J. Homeostatic maintenance of T cells and natural killer cells. Cell Mol Life Sci (2012) 69:1597-608. doi:10.1007/ s00018-012-0968-7

39. Singer A, Adoro S, Park JH. Lineage fate and intense debate: myths, models and mechanisms of CD4- versus CD8-lineage choice. Nat Rev Immunol (2008) 8:788-801. doi:10.1038/nri2416

40. PeschonJJ,MorrisseyPJ,Grabstein KH,RamsdellFJ,MaraskovskyE, GliniakBC, et al. Early lymphocyte expansion is severely impaired in interleukin 7 receptor-deficient mice. JExp Med (1994) 180:1955-60. doi:10.1084/jem.180. 5.1955

41. Hong C, Luckey MA, Park JH. Intrathymic IL-7: the where, when, and why of IL-7 signaling during T cell development. Semin Immunol (2012) 24:151-8. doi:10.1016/j.smim.2012.02.002

42. Tan JT, Dudl E, LeRoy E, Murray R, Sprent J, Weinberg KI, et al. IL-7 is critical for homeostatic proliferation and survival of naïve T cells. Proc Natl Acad Sci U S A (2001) 98:8732-7. doi:10.1073/pnas.161126098

43. Bosco N, Agenes F, Ceredig R. Effects of increasing IL-7 availability on lymphocytes during and after lymphopenia-induced proliferation. J Immunol (2005) 175:162-70. doi:10.4049/jimmunol.175.1.162

44. Ceredig R, Rolink AG. The key role of IL-7 in lymphopoiesis. Semin Immunol (2012) 24:159-64. doi:10.1016/j.smim.2012.02.004

45. Mertsching E, Burdet C, Ceredig R. IL-7 transgenic mice: analysis of the role of IL-7 in the differentiation of thymocytes in vivo and in vitro. Int Immunol (1995) 7:401-14. doi:10.1093/intimm/7.3.401
46. Rich BE, Campos-Torres J, Tepper RI, Moreadith RW, Leder P. Cutaneous lymphoproliferation and lymphomas in interleukin 7 transgenic mice. J Exp Med (1993) 177:305-16. doi:10.1084/jem.177.2.305

47. Boyman O, Ramsey C, Kim DM, Sprent J, Surh CD. IL-7/anti-IL-7 mAb complexes restore $\mathrm{T}$ cell development and induce homeostatic $\mathrm{T}$ Cell expansion without lymphopenia. J Immunol (2008) 180:7265-75. doi:10.4049/ jimmunol.180.11.7265

48. Komschlies KL, Gregorio TA, Gruys ME, Back TC, Faltynek CR, Wiltrout RH. Administration of recombinant human IL-7 to mice alters the composition of B-lineage cells and $\mathrm{T}$ cell subsets, enhances $\mathrm{T}$ cell function, and induces regression of established metastases. J Immunol (1994) 152:5776-84.

49. Geiselhart LA, Humphries CA, Gregorio TA, Mou S, Subleski J, Komschlies KL. IL-7 administration alters the CD4:CD8 ratio, increases $\mathrm{T}$ cell numbers, and increases $\mathrm{T}$ cell function in the absence of activation. J Immunol (2001) 166:3019-27. doi:10.4049/jimmunol.166.5.3019

50. Min B, Yamane H, Hu-Li J, Paul WE. Spontaneous and homeostatic proliferation of CD4 T cells are regulated by different mechanisms. J Immunol (2005) 174:6039-44. doi:10.4049/jimmunol.174.10.6039

51. Seddon B, Zamoyska R. TCR and IL-7 receptor signals can operate independently or synergize to promote lymphopenia-induced expansion of naïve T cells. J Immunol (2002) 169:3752-9. doi:10.4049/jimmunol.169.7.3752

52. Boursalian TE, Bottomly K. Survival of naïve CD4 T cells: roles of restricting versus selecting MHC class II and cytokine milieu. J Immunol (1999) 162:3795-801.

53. van Lent AU, Dontje W, Nagasawa M, Siamari R, Bakker AQ, Pouw SM, et al. IL-7 enhances thymic human T cell development in "human immune system" Rag2-/-IL-2Rgammac-/- mice without affecting peripheral T cell homeostasis. J Immunol (2009) 183:7645-55. doi:10.4049/jimmunol.0902019

54. McCaughtry TM, Etzensperger R, Alag A, Tai X, Kurtulus S, Park JH, et al. Conditional deletion of cytokine receptor chains reveals that IL-7 and IL-15 specify CD8 cytotoxic lineage fate in the thymus. J Exp Med (2012) 209:2263-76. doi:10.1084/jem.20121505

55. Kimura MY, Pobezinsky LA, Guinter TI, Thomas J, Adams A, Park JH, et al. IL-7 signaling must be intermittent, not continuous, during CD8(+) T cell homeostasis to promote cell survival instead of cell death. Nat Immunol (2013) 14:143-51. doi:10.1038/ni.2494

56. Guimond M, Veenstra RG, Grindler DJ, Zhang H, Cui Y, Murphy RD, et al. Interleukin 7 signaling in dendritic cells regulates the homeostatic proliferation and niche size of CD4+ T cells. Nat Immunol (2009) 10:149-57. doi:10.1038/ni.1695

57. Osborne LC, Patton DT, Seo JH, Abraham N. Elevated IL-7 availability does not account for $\mathrm{T}$ cell proliferation in moderate lymphopenia. J Immunol (2011) 186:1981-8. doi:10.4049/jimmunol.1002224

58. Kisielow P, Teh HS, Bluthmann H, von Boehmer H. Positive selection of antigen-specific T cells in thymus by restricting MHC molecules. Nature (1988) 335:730-3. doi:10.1038/335730a0

59. Jameson SC, Hogquist KA, Bevan MJ. Positive selection of thymocytes. Annu Rev Immunol (1995) 13:93-126. doi:10.1146/annurev.iy.13.040195.000521

60. Kirberg J, Berns A, von Boehmer H. Peripheral T cell survival requires continual ligation of the $\mathrm{T}$ cell receptor to major histocompatibility complex-encoded molecules. J Exp Med (1997) 186:1269-75. doi:10.1084/ jem.186.8.1269

61. Fischer UB, Jacovetty EL, Medeiros RB, Goudy BD, Zell T, Swanson JB, et al. MHC class II deprivation impairs CD4 T cell motility and responsiveness to antigen-bearing dendritic cells in vivo. Proc Natl Acad Sci U S A (2007) 104:7181-6. doi:10.1073/pnas.0608299104

62. Do JS, Min B. Differential requirements of MHC and of DCs for endogenous proliferation of different T-cell subsets in vivo. Proc Natl Acad Sci U S A (2009) 106:20394-8. doi:10.1073/pnas.0909954106

63. Viret C, Wong FS, Janeway CA Jr. Designing and maintaining the mature TCR repertoire: the continuum of self-peptide:self-MHC complex recognition. Immunity (1999) 10:559-68. doi:10.1016/S1074-7613(00)80055-2

64. Bender J, Mitchell T, Kappler J, Marrack P. CD4+ T cell division in irradiated mice requires peptides distinct from those responsible for thymic selection. J Exp Med (1999) 190:367-74. doi:10.1084/jem.190.3.367

65. Takeda S, Rodewald HR, Arakawa H, Bluethmann H, Shimizu T. MHC class II molecules are not required for survival of newly generated CD4+ T cells, but affect their long-term life span. Immunity (1996) 5:217-28. doi:10.1016/ S1074-7613(00)80317-9 
66. Revy P, Sospedra M, Barbour B, Trautmann A. Functional antigen-independent synapses formed between T cells and dendritic cells. Nat Immunol (2001) 2:925-31. doi:10.1038/ni713

67. Grandjean I, Duban L, Bonney EA, Corcuff E, Di Santo JP, Matzinger P, et al. Are major histocompatibility complex molecules involved in the survival of naïve CD4+ T cells? J Exp Med (2003) 198:1089-102. doi:10.1084/ jem.20030963

68. Clarke SR, Rudensky AY. Survival and homeostatic proliferation of naïve peripheral CD4+ T cells in the absence of self peptide:MHC complexes. J Immunol (2000) 165:2458-64. doi:10.4049/jimmunol.165.5.2458

69. Witherden D, van Oers N, Waltzinger C, Weiss A, Benoist C, Mathis D. Tetracycline-controllable selection of CD4(+) T cells: half-life and survival signals in the absence of major histocompatibility complex class II molecules. J Exp Med (2000) 191:355-64. doi:10.1084/jem.191.2.355

70. Dorfman JR, Germain RN. MHC-dependent survival of naïve T cells? A complicated answer to a simple question. Microbes Infect (2002) 4:547-54. doi:10.1016/S1286-4579(02)01571-X

71. Jameson SC. T cell homeostasis: keeping useful $\mathrm{T}$ cells alive and live T cells useful. Semin Immunol (2005) 17:231-7. doi:10.1016/j.smim.2005. 02.003

72. Martin B, Bourgeois C, Dautigny N, Lucas B. On the role of MHC class II molecules in the survival and lymphopenia-induced proliferation of peripheral
CD4+ T cells. Proc Natl Acad Sci U S A (2003) 100:6021-6. doi:10.1073/ pnas. 1037754100

73. Martin B, Becourt C, Bienvenu B, Lucas B. Self-recognition is crucial for maintaining the peripheral CD4+ T-cell pool in a nonlymphopenic environment. Blood (2006) 108:270-7. doi:10.1182/blood-2006-01-0017

74. Al-Herz W, Alsmadi O, Melhem M, Recher M, Frugoni F, Notarangelo LD. Major histocompatibility complex class II deficiency in Kuwait: clinical manifestations, immunological findings and molecular profile. J Clin Immunol (2013) 33:513-9. doi:10.1007/s10875-012-9831-8

75. Hogquist KA. Immunodeficiency: when $\mathrm{T}$ cells are stuck at home. Nat Immunol (2008) 9:1207-8. doi:10.1038/ni1108-1207

Conflict of Interest Statement: The authors declare that the research was conducted in the absence of any commercial or financial relationships that could be construed as a potential conflict of interest.

Copyright (C) 2018 Mori and Pieters. This is an open-access article distributed under the terms of the Creative Commons Attribution License (CC BY). The use, distribution or reproduction in other forums is permitted, provided the original author (s) and the copyright owner(s) are credited and that the original publication in this journal is cited, in accordance with accepted academic practice. No use, distribution or reproduction is permitted which does not comply with these terms. 